\title{
Produção de biogás através de codigestão anaeróbia de resíduos orgânicos industriais e urbanos
}

Visando minimizar os impactos ambientais, como a contaminação de solo, água e atmosfera, causados pela geração de resíduos da agroindústria, pecuária e dos centros urbanos, o aproveitamento energético destes resíduos surge como alternativa. Caracterizada como uma tecnologia de tratamento biológico, a biodigestão anaeróbia além de reduzir o teor de matéria orgânica do resíduo, produz biogás capaz de gerar energia. Por conta de diversas variáveis e condições afetarem a produção deste biocombustível, a codigestão de resíduos orgânicos agrega positivamente, em muitos casos, na eficiência da produção de biogás, levando-se em consideração o alcance de uma melhor condição de nutrientes, bem como a temperatura é fator de grande importância. 0 objetivo deste trabalho, portanto, fo determinar o potencial de geração de biogás proveniente da codigestão de efluente oriundo da produção de arroz parboilizado com resíduos sólidos orgânicos oriundos do Restaurante Universitário da Universidade Federal de Pelotas e outra codigestão utilizando apenas os resíduos gerados pelo Restaurante Universitário. $\mathrm{O}$ experimento foi realizado durante 252 horas em temperatura ambiente e à $35^{\circ} \mathrm{C}$. Como principal resultado observou-se que a codigestão com efluente oriundo do processo de parboilização do arroz mantida à $35^{\circ} \mathrm{C}$ apresentou maior eficiência na produção de biogás com volume de aproximadamente 7,45 dm ${ }^{3}$.

\section{Biogas production through anaerobic codigestion of industrial and urban organic waste}

\begin{abstract}
In order to minimize environmental impacts, such as contamination of soil, water and atmosphere, caused by the generation of residues from agribusiness, livestock and urban centers, the energy use of these residues appears as an alternative. Characterized as a biological treatment technology, anaerobic biodigestion, besides reducing the organic matter content of the waste, produces biogas capable of generating energy. Because several variables and conditions affect the production of this biofuel, organic waste codigestion positively adds, in many cases, in the efficiency of biogas production, taking into account the reach of a better nutrient condition, as well as the temperature factor of great importance. The objective of this work, therefore, was to determine the potential for biogas generation from effluent codigestion from the production of parboiled rice with organic solid waste from the University Restaurant of the Federal University of Pelotas and other codigestion using only the waste generated by the University Restaurant. The experiment was performed for 252 hours at room temperature and at $35^{\circ} \mathrm{C}$. As main result, it was observed that the effluent codigestion from the rice parboiling process maintained at $35^{\circ} \mathrm{C}$ showed higher efficiency in the production of biogas with a volume of approximately $7.45 \mathrm{dm}^{3}$
\end{abstract}

Keywords: Bioenergy; Anaerobic biodigestion; Organic waste; Renewable energy.

Topic: Desenvolvimento, Sustentabilidade e Meio Ambiente

Reviewed anonymously in the process of blind peer.
Received: 05/10/2020

Approved: 26/11/2020
Willian Cézar Nadaleti (iD)

Universidade Federal de Pelotas, Brasil http://lattes.cnpq.br/4670559561277136 http://orcid.org/0000-0002-4727-4127 williancezarnadaletti@gmail.com

Vitor Alves Lourenço

Universidade de São Paulo, Brasil http://lattes.cnpq.br/0540242108317748 http://orcid.org/0000-0003-3940-7812 vitor.a.lourenco@gmail.com

Gabriel Borges dos Santos (iD Universidade Federal de Pelotas, Brasil http://lattes.cnpq.br/8502930511377553 http://orcid.org/0000-0002-0013-0134 gabrielwxsantos@hotmail.com
Eduarda Gomes de Souza (iD) Universidade Federal de Pelotas, Brasil http://lattes.cnpq.br/0999718187034675 http://orcid.org/0000-0001-7166-2018 gseduarda@gmail.com

Gabriel Américo Alves dos Santos Universidade Federal de Pelotas, Brasil http://lattes.cnpq.br/6098809947083490 gabriel.americo996@gmail.com

Anaís França de Matos Oliveir Universidade Federal de Pelotas, Brasil http://lattes.cnpq.br/4972641617559480 anais.franca@uol.com.br

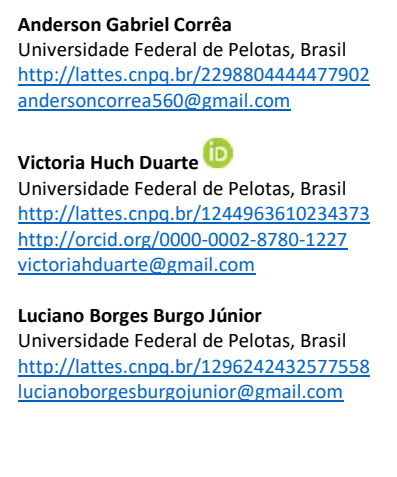

Bruno Müller Vieira (iD)

Universidade Federal de Pelotas, Brasil http://lattes.cnpq.br/1885554662703620 http://orcid.org/0000-0002-9615-3778 bruno.prppg@hotmail.com

Renan de Freitas Santos Universidade Federal de Pelotas, Brasil http://lattes.cnpq.br/5554896977518652 reh.8@hotmail.com

DOI: 10.6008/CBPC2179-6858.2020.006.0035

Referencing this:

NADALETI, W. C.; LOURENÇO, V. A.; SANTOS, G. B.; SOUZA, E. G.; SANTOS, G. A. A.; OLIVEIRA, A. F. M.; CORRÊA, A. G.; DUARTE, V. H.; BURGO JUNIOR, L. B.; VIEIRA, B. M.; SANTOS, R. F.. Produção de biogás através de codigestão anaeróbia de resíduos orgânicos industriais $e$ urbanos. Revista Ibero Americana de Ciências Ambientais, v.11, n.6, p.428-439, 2020. DOI: http://doi.org/10.6008/CBPC21796858.2020 .006 .0035 


\section{INTRODUÇÃO}

Os padrões atuais de produção e consumo de alimentos são considerados insustentáveis, onde a agricultura é o uso da terra mais dominante no planeta e continuará assim, à medida que a população mundial e a demanda global de alimentos aumentarem (TANENTZAP et al., 2015). Os resíduos oriundos da produção de alimentos e do consumo humano estão entre os principais impulsionadores da degradação ambiental (NOTARNICOLA et al., 2017).

Uma categoria importante de resíduos produzidos em grande escala ao redor do mundo são os resíduos orgânicos (SITORUS et al., 2013). Em 2011, aproximadamente, 1728 milhões de toneladas de frutas e legumes foram produzidos em todo o mundo, onde o Brasil possui uma posição de liderança neste mercado, sendo o terceiro maior produtor de frutas no mundo e o terceiro maior produtor de vegetais das Américas (FAO, 2014).

O Brasil encontra-se entre os dez maiores produtores de arroz do mundo, produzindo cerca de 12 milhões de toneladas por ano e tendo o Rio Grande do Sul como Estado de maior rendimento (FAO, 2018). A estimativa obtida pela Food and Agriculture Organization of the United Nations indica uma produção de 770 milhões de toneladas em 2018, demonstrando a relevância econômica e o papel nutricional das lavouras de arroz no cenário global (FAO, 2018).

Segundo Buggenhout et al. (2013), cerca de $20 \%$ do arroz mundial é parboilizado. A parboilização pode efetivamente alterar características físicas (resistência à ruptura, por exemplo) e texturais, bem como melhorar os valores nutricionais (SITTIPOD et al., 2016). No processo de parboilização do arroz, porém, gerase cerca de 4 litros de efluente por quilo de arroz beneficiado, o qual possui elevadas taxas de substâncias orgânicas havendo, portanto, a necessidade do tratamento deste efluente com a finalidade de garantir qualidade suficiente para que o mesmo possa ser reintroduzido em corpos hídricos ou ser reutilizado (FARIA et al., 2006).

Os resíduos provenientes da indústria de alimentos e do consumo humano podem ser utilizados através da tecnologia de biodigestão anaeróbica (KOUPAIE et al., 2014). Neste processo, os principais fatores ambientais que interferem são a temperatura, que deve ser ajustada a um estágio mesofílico $\left(25\right.$ a $\left.40^{\circ} \mathrm{C}\right)$ ou termofílico $\left(45 \mathrm{a} 60^{\circ} \mathrm{C}\right)$, e o pH, que deve estar próximo à neutralidade, salientando-se que a composição do resíduo orgânico também influencia na eficiência do processo, uma vez que o teor de carboidratos (açúcares redutores, amido, celulose, hemicelulose e lignina), lipídios (ácidos graxos voláteis) e proteínas estarão em função do tipo e origem de cada resíduo (GONZÁLEZ-SÁNCHEZ et al., 2015).

No processo de biodigestão anaeróbia ocorre a conversão de matéria orgânica em biogás, o qual contém entre 55 e $65 \%$ de metano, 35 e $45 \%$ de dióxido de carbono e pequenas frações de outros gases (BALAT et al., 2009). A codigestão anaeróbia une diferentes tipos de resíduos passíveis de fermentação que são misturados e tratados conjuntamente, ressaltando-se que este processo pode ser aplicado objetivando um melhor rendimento no processo de biodigestão anaeróbia, podendo promover, por exemplo, o equilíbrio de nutrientes, bem como o aumento da quantidade de material orgânico com maior potencial de 
biodegradabilidade (LEITE et al., 2017).

O biogás é produzido através de uma série de fases que ocorrem na ausência de oxigênio (processo anaeróbio), onde ocorre inicialmente a fase de hidrólise, na qual se encontram as bactérias fermentativas, posteriormente se encontram as fases acidogênica e acetogênica, para que se alcance, ao fim, a fase metanogênica, onde o metano é formado (THEMELIS et al., 2007).

A produção de biogás, a partir da biodigestão anaeróbia, constitui-se como uma excelente fonte de bioenergia, tendo potencial para aliviar parcialmente a dependência mundial dos combustíveis fósseis. Em busca de soluções ambientalmente viáveis para os diferentes tipos de resíduos orgânicos, esta pesquisa busca descrever e discutir sobre um método para a codigestão anaeróbia de resíduos industriais e urbanos, a fim de obter-se um melhoramento na produção de biogás.

\section{METODOLOGIA}

\section{Confecção dos biodigestores e medidores}

Os biodigestores utilizados no presente estudo foram confeccionados no Laboratório de Engenharia Ambiental e Energia da Universidade Federal de Pelotas (UFPel), onde a pesquisa foi desenvolvida. Para a confecção dos biodigestores foram reutilizadas garrafas de Politereftalato de Etileno (PET) de 1 litro, com um volume total de $1,065 \mathrm{dm}^{3}$, a fim de operarem com eficiência e baixo custo. Visando a comunicação de cada biodigestor com seu respectivo medidor, foi necessária à instalação de conexões entre os recipientes e para tal realizou-se a inserção de um tubo flexível de silicone com $4 \mathrm{~mm}$ de diâmetro, no centro superior do biodigestor. O tubo instalado foi vedado com silicone acético incolor, inibindo futuras perdas de biogás para a atmosfera. Tendo em vista a não interferência da luminosidade nos processos de codigestão, cada biodigestor foi revestido com papel adesivo preto.

A elaboração do sistema de medição foi realizada a partir do princípio do deslocamento de líquidos entre dois frascos comunicantes (graduado e reservatório) conectados ao biodigestor, onde o frasco graduado é conectado à parte superior do reator através do tubo flexível e recebeu graduação de volume em mililitros, para quantificação do biogás gerado (Figura 1). O reservatório faz-se imprescindível para o armazenamento do líquido que será deslocado através do medidor pelo biogás gerado, o qual possui uma abertura com saída para a atmosfera. Visto que o volume de líquido deslocado corresponde ao volume de gás gerado no biodigestor, os recipientes foram preenchidos com uma pipeta volumétrica de $5 \mathrm{em} 5 \mathrm{~mL}$, assim foi possível graduar o medidor a cada $5 \mathrm{~mL}$.

Foi inserido um divisor de ar modular valve terminal na entrada de cada medidor, o qual garante a saída do gás para atmosfera quando aberto, possibilitando o retorno do líquido para sua marca inicial. Logo, ao fim de cada medição, o sistema pode liberar para atmosfera o biogás já quantificado, zerando-se o medidor. Os medidores, ademais, receberam uma fina camada de óleo de soja (10 mL) acima do nível de água contida no medidor graduado, para evitar a dissolução do dióxido de carbono $\left(\mathrm{CO}_{2}\right)$ contido no biogás. 


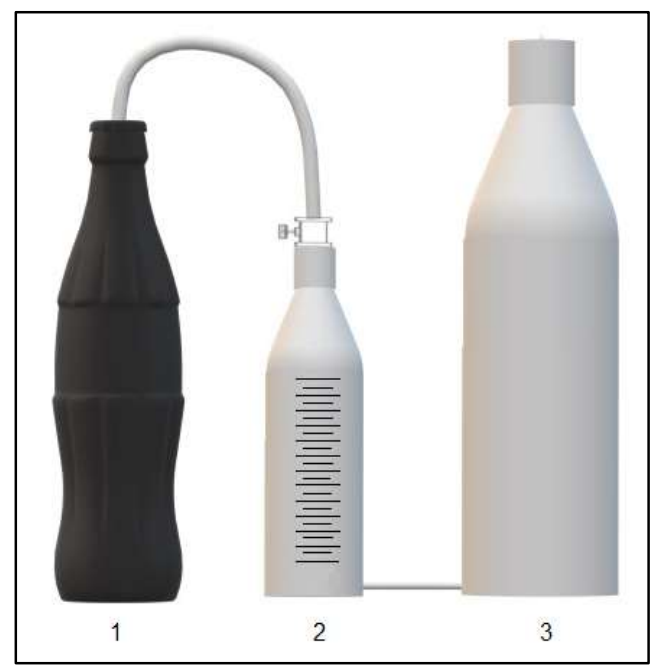

Figura 1: Biodigestor conectado ao medidor de biogás. Onde: 1. Biodigestor; 2. Frasco graduado; 3 . Reservatório.

\section{Alimentação e condicionamento dos biodigestores}

Cada biodigestor foi nomeado de acordo com a sua alimentação, onde seis receberam a letra $\mathrm{R}$ e continham resíduos sólidos orgânicos do Restaurante Universitário, enquanto outros seis receberam a nomeação RE contendo, além dos resíduos alimentares, efluente oriundo do processo da parboilização de arroz. Em todos os biodigestores adicionou-se, ainda, lodo oriundo do processo da parboilização de arroz, o qual funciona como inóculo no sistema.

A operação dos biodigestores foi realizada em batelada simples, recebendo alimentação somente no início de seu ciclo. Para quantificar o volume de cada matéria orgânica introduzida nos biodigestores foram utilizadas provetas graduadas. Realizou-se uma triplicata para cada composição (R e RE) controlandose a temperatura de $35^{\circ} \mathrm{C}$, com o auxílio de um banho de aquecimento com termostato Fisatom (modelo 572). Devido à evaporação da água no decorrer do experimento, ao longo dos dias foi necessário o reabastecimento do banho de aquecimento a fim de manter o nível adequado de água. Outras duas triplicatas (R e RE) foram mantidas em temperatura ambiente, em média, à $22^{\circ} \mathrm{C}$.

O efluente e o lodo introduzidos nos biodigestores foram obtidos do UASB (Upflow Anaerobic Sludge Blanket Reactor) de uma estação de tratamento de efluentes de uma indústria de beneficiamento de arroz localizada no município de Pelotas, Estado do Rio Grande do Sul, Brasil. Já os resíduos sólidos orgânicos alimentares foram provenientes do descarte da cozinha do Restaurante Universitário da Universidade Federal de Pelotas. Tais resíduos foram coletados e transportados ao Laboratório de Engenharia Ambiental e Energia, onde os alimentares foram submetidos aos processos de caracterização, trituração e diluição.

A caracterização foi realizada a partir da disposição dos mesmos sob uma lona de polipropileno com dimensões de $3 \times 3 \mathrm{~m}$, na qual foram segregados e quantificados totalizando 4 classes de resíduos, sendo elas: hortifruti, proteína de soja, carne bovina e grãos. Os resíduos foram triturados e diluídos, onde para cada $100 \mathrm{~g}$ de resíduo foi adicionado $200 \mathrm{~mL}$ de água destilada, estabelecendo uma relação 1:2.

A trituração e diluição dos resíduos gerou uma solução utilizada como substrato nos Biodigestores $R$. Para o substrato utilizado nos Biodigestores RE, realizou-se uma composição entre a solução de resíduos 
alimentares (30\%) juntamente com o efluente (40\%). Nos reatores R e RE adicionou-se $255,6 \mathrm{~mL}$ de lodo e $596,4 \mathrm{~mL}$ de substrato.

Relacionando-se as diferentes temperaturas e composições de substrato, cada biodigestor recebeu uma nomeação para facilitar a quantificação do biogás produzido, onde RE (1 a 3) e R (4 a 6) foram mantidos à $35^{\circ} \mathrm{C}$, já RE (7 a 9) e R (10 a 12) foram mantidos em temperatura ambiente ( $\left.22^{\circ} \mathrm{C}\right)$. Pôde-se, assim, realizar uma média entre as triplicatas e numerar com a respectiva temperatura de operação, resultando-se nos biodigestores R22, RE22, R35 e RE35.

As medições foram realizadas diariamente de 12 em 12 horas por um período de 252 horas, zerandose o medidor a cada intervalo até ocorrer o decaimento da produção de biogás. No término do experimento adicionou-se ao volume obtido através da escala do medidor, o volume de 0,213 $\mathrm{dm}^{3}$ referente ao headspace, local reservado para a formação das bolhas de biogás, totalizando $20 \%$ do volume total do biodigestor. Os biodigestores operaram, portanto, com um volume útil de $0,852 \mathrm{dm}^{3}$.

\section{Coleta dos resíduos}

Os resíduos foram coletados, antes de iniciar-se o experimento, para serem realizadas análises de Demanda Química de Oxigênio (DQO) e potencial hidrogeniônico $(\mathrm{pH})$. A solução de resíduos alimentares e a composição da mesma com efluente oriundo da produção de arroz parboilizado foram depositadas em frascos distintos de polipropileno com tampa lacre batocada contendo $250 \mathrm{~mL}$. Após o término do experimento realizou-se a coleta dos efluentes de cada Biodigestor, com intuito de realizar-se análises de DQO e pH. Todos os frascos, após as coletas, foram refrigerados para que não houvesse interferência nas análises.

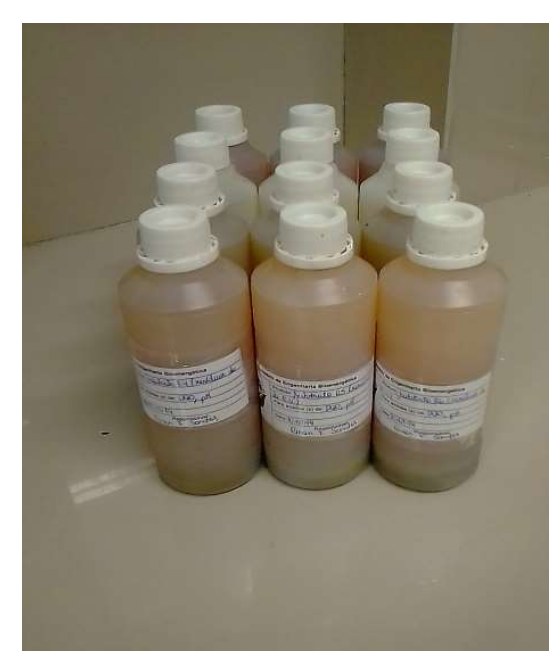

Figura 2: Frascos identificados.

O efluente contido em cada biodigestor foi filtrado utilizando-se papel filtro com diâmetro de $9 \mathrm{~cm}$. Com o auxílio de um copo bécker de $50 \mathrm{~mL}$, separou-se a fração líquida da sólida. A fração líquida contida no copo bécker foi, então, inserida nos frascos de polipropileno com tampa lacre batocada. Os frascos foram identificados para diferenciar os resíduos contidos em cada biodigestor (Figura 2). 


\section{Análise de Demanda Química de Oxigênio (DQO)}

O armazenamento, preservação, análise e resultados das amostras seguiram a metodologia adaptada do Standard Methods for the Examination of Water \& Wastewater (APHA et al., 2005). O processo de realização da análise de DQO iniciou-se com a limpeza dos tubos, onde foram alocados em um banho de ácido sulfúrico $20 \%$ por $24 \mathrm{~h}$, posteriormente, foram enxaguados com água destilada e devidamente secos.

Após a secagem dos tubos, adicionou-se $1,5 \mathrm{~mL}$ de dicromato de potássio (solução de digestão). Adicionou-se, lentamente pelas paredes do tubo, $3,5 \mathrm{~mL}$ de ácido sulfúrico. Após a adição dos reagentes homogeneizou-se a mistura. Para as análises de entrada dos Biodigestores R utilizou-se uma diluição de 350:1 e para os Biodigestores RE 200:1. Para as análises de saída dos Biodigestores RE35 utilizou-se uma diluição de 25:1, para os Biodigestores R35 100:1, para os Biodigestores RE22 40:1 e para os Biodigestores R22 120:1.

Adicionou-se 2,5 mL de uma porção das amostras devidamente diluídas e identificou-se cada tubo. Para o Branco adicionou-se 2,5 mL de água destilada e para o Padrão 2,5 mL da solução de biftalato de hidrogênio e potássio, diluída 5 vezes. Após tampá-los, os tubos foram homogeneizados cuidadosamente evitando-se o contato do conteúdo na tampa.

Colocaram-se os tubos no dry block à $150^{\circ} \mathrm{C}$ por duas horas (Figura 3). Desligou-se o equipamento, após o término de duas horas, porém os frascos foram deixados no equipamento até esfriarem, a fim de evitar-se possíveis trincamentos.

Transferiu-se o conteúdo de cada tubo para diferentes frascos erlenmeyer de $50 \mathrm{~mL}$ e adicionou-se 3 gotas de solução indicadora ferroína em cada um deles. As amostras foram tituladas com sulfato ferroso amoniacal utilizando uma bureta de $10 \mathrm{~mL}$, onde visualizou-se a mudança de coloração do verde azulado para o marrom avermelhado (Figura 4).

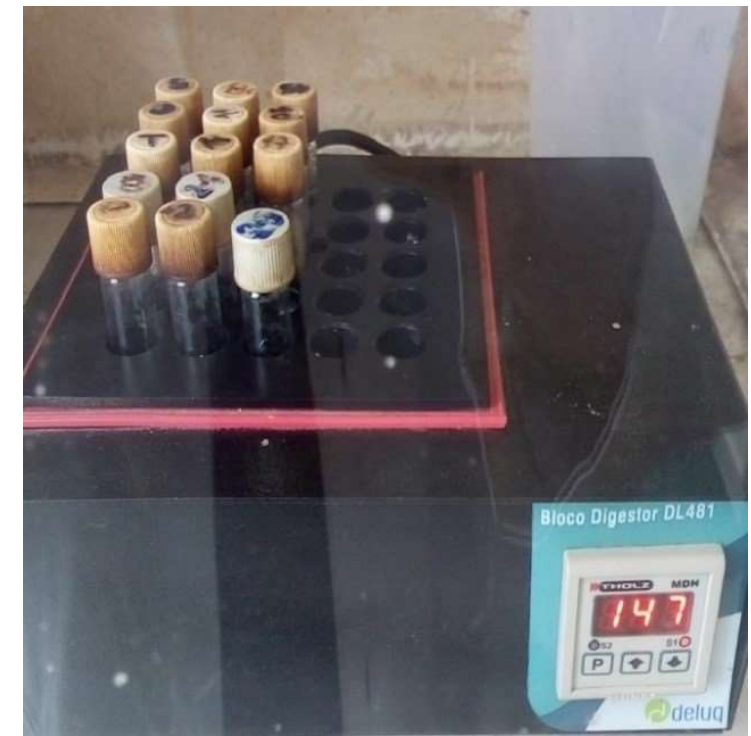

Figura 3: Tubos aquecendo no Dry Block.

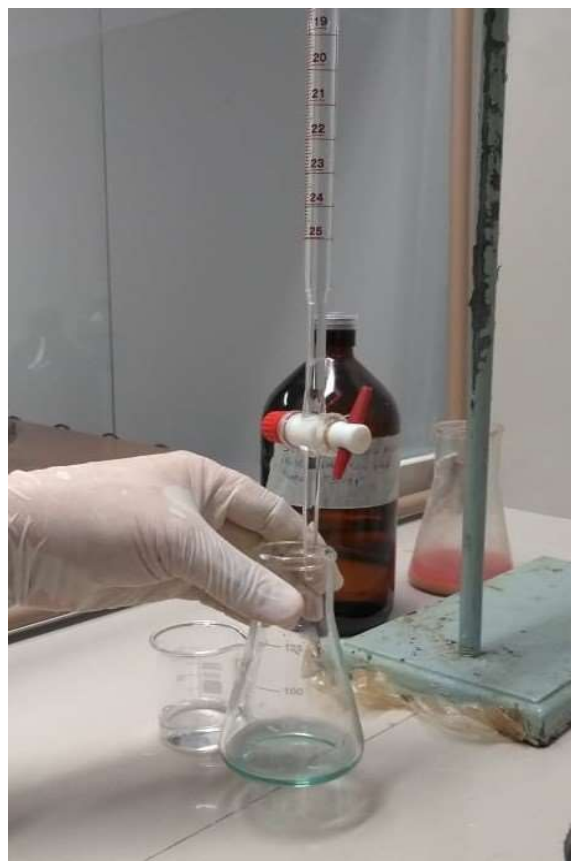

Figura 4: Titulação da amostra. 
Realizou-se a padronização do sulfato ferroso amoniacal (titulante) a cada análise, onde em um erlenmeyer de $125 \mathrm{~mL}$ adicionou-se $5 \mathrm{~mL}$ de solução de digestão (dicromato de potássio), $40 \mathrm{~mL}$ de água destilada e $5 \mathrm{~mL}$ de ácido sulfúrico P.A., respectivamente. Para determinar-se a DQO utilizou-se a Equação 1:

$$
\text { DQO em } \mathrm{mg} \mathrm{O}_{2} \cdot L^{-1}=\frac{(A-B) \times C \times F n \times 8000}{V \text { amostra }(m L) \times F d}
$$

Equação 1

Onde:

A - Volume gasto de titulante no branco; B - Volume gasto de titulante na amostra;

C - Concentração da solução;

Fn - Fator normal do titulante; Fd - Fator de diluição da amostra.

\section{Análise do potencial Hidrogeniônico $(\mathrm{pH})$}

A determinação do pH é baseada no método potenciométrico, no qual a medida da atividade do íon hidrogênio é verificada com um eletrodo padrão de hidrogênio e um de referência. As análises e resultados das amostras seguiram a metodologia adaptada do Standard Methods for the Examination of Water \& Wastewater (APHA et al., 2005).

Calibrou-se o equipamento conforme seu manual de instruções e manteve-se o eletrodo sempre imerso em solução saturada de $\mathrm{KCl}_{3} \mathrm{M}$. Antes do uso, retirou-se o eletrodo da solução de estocagem, enxaguou-se com água destilada e secou-se com papel suave. Antes de iniciar a análise, conferiu-se a calibração com o padrão pH 7.

Colocou-se a amostra em um béquer previamente ambientado e ajustou-se o béquer e os eletrodos de forma que a amostra pôde ser homogeneizada. Imergiu-se juntamente com o eletrodo o compensador de temperatura, aguardou-se a estabilização do equipamento e anotou-se o valor observado.

\section{DISCUSSÃO TEÓRICA}

De acordo com Carneiro (2009), em se tratando dos procedimentos considerados na digestão anaeróbia, na maioria dos casos as temperaturas aplicadas estão entre 30 e $40^{\circ} \mathrm{C}$. Nesta faixa de temperatura a produção de biogás ocorre de maneira eficiente e necessita de menor gasto energético para manter a quantidade de calor no digestor (KIM et al., 2002). Considerando-se o fator temperatura, portanto, esperavase que os Biodigestores mantidos à $35^{\circ} \mathrm{C}$ obtivessem resultados mais satisfatórios quando comparados aos Biodigestores mantidos em temperatura ambiente $\left(22^{\circ} \mathrm{C}\right)$.

Após realizadas as análises da Demanda Química de Oxigênio (DQO), utilizou-se a Equação 1 para quantificar os resultados descritos na Tabela 1. Os resultados considerados foram as médias das triplicatas realizadas no experimento.

Tabela 1: Análises da Demanda Química de Oxigênio (DQO).

\begin{tabular}{|c|c|c|c|c|c|c|}
\hline Amostra & $\begin{array}{ll}\text { Entrada } & \text { (mg } \\
\text { de } 0_{2} / \mathrm{L} \text { ) } & \\
\end{array}$ & $\begin{array}{l}\text { Média da entrada } \\
\text { ( } \mathrm{mg} \mathrm{de} \mathrm{O}_{2} / \mathrm{L} \text { ) }\end{array}$ & $\begin{array}{l}\text { Saída (mg de } \\
0_{2} / \mathrm{L} \text { ) }\end{array}$ & $\begin{array}{l}\text { Média da saída } \\
\text { ( } \mathrm{mg} \text { de } \mathrm{O}_{2} / \mathrm{L} \text { ) }\end{array}$ & $\begin{array}{l}\text { Remoção de } \\
\text { DQO (\%) }\end{array}$ & $\begin{array}{l}\text { Média da remoção } \\
\text { de DQO (\%) }\end{array}$ \\
\hline RE1 & 44356,44 & \multirow{3}{*}{44356,44} & 3301,59 & \multirow{3}{*}{3470,9} & 92,56 & \multirow{3}{*}{92,17} \\
\hline RE2 & 44356,44 & & 4825,40 & & 89,12 & \\
\hline RE3 & 44356,44 & & 2285,71 & & 94,85 & \\
\hline
\end{tabular}




\begin{tabular}{|c|c|c|c|c|c|c|}
\hline R4 & 66534,65 & \multirow{3}{*}{66534,65} & 22349,21 & \multirow{3}{*}{20994,71} & 66,41 & \multirow{3}{*}{68,45} \\
\hline R5 & 66534,65 & & 24380,95 & & 63,36 & \\
\hline R6 & 66534,65 & & 16253,97 & & 75,57 & \\
\hline RE7 & 44356,44 & \multirow{3}{*}{44356,44} & 8888,89 & \multirow{3}{*}{8888,89} & 79,96 & \multirow{3}{*}{79,96} \\
\hline RE8 & 44356,44 & & 8888,89 & & 79,96 & \\
\hline RE9 & 44356,44 & & 8888,89 & & 79,96 & \\
\hline R10 & 66534,65 & \multirow{3}{*}{66534,65} & 32592,59 & \multirow{3}{*}{32197,53} & 51,01 & \multirow{3}{*}{51,61} \\
\hline R11 & 66534,65 & & 32592,59 & & 51,01 & \\
\hline R12 & 66534,65 & & 31407,41 & & 52,80 & \\
\hline
\end{tabular}

Nota-se que o Biodigestor RE35 alcançou a maior remoção de DQO em relação aos diferentes estudos realizados, onde constatou-se $92,17 \%$ de remoção. Este fato pode ser explicado pela temperatura de operação, bem como pela composição dos resíduos orgânicos nele contidos (efluente do processo de parboilização de arroz e resíduos oriundos do Restaurante Universitário). Já o Biodigestor R35 não obteve resultados similares ao Biodigestor RE35, o que pode ser explicado pela diferente composição de resíduos contidos em cada um deles.

Constatou-se uma maior remoção de DQO no Biodigestor RE22 (79,96\%), quando comparado ao Biodigestor R35 (68,45\%). Nota-se que mesmo operando em maior temperatura, o que teoricamente beneficiaria o Biodigestor R35, seu resultado foi inferior, o que pode ser compreendido considerando a composição dos resíduos contidos em cada um deles. Já o Biodigestor R22 obteve a menor remoção de DQO, alcançando 51,61\%.

Os valores obtidos nas análises de $\mathrm{pH}$ das amostras de entrada e saída podem ser observados na Tabela 2. Os resultados considerados correspondem aos valores médios obtidos.

Tabela 2: Valores de $\mathrm{pH}$ de entrada e saída nos Biodigestores.

\begin{tabular}{|c|c|c|c|c|}
\hline Biodigestor & Entrada & Entrada média & Saída & Saída média \\
\hline RE1 & 4,25 & \multirow{3}{*}{4,25} & 7,43 & \multirow{3}{*}{7,43} \\
\hline RE2 & 4,25 & & 7,35 & \\
\hline RE3 & 4,25 & & 7,51 & \\
\hline R4 & 5,8 & \multirow{3}{*}{5,8} & 7,12 & \multirow{3}{*}{7,1} \\
\hline R5 & 5,8 & & 6,97 & \\
\hline R6 & 5,8 & & 7,21 & \\
\hline RE7 & 4,25 & \multirow{3}{*}{4,25} & 7,28 & \multirow{3}{*}{7,27} \\
\hline RE8 & 4,25 & & 7,27 & \\
\hline RE9 & 4,25 & & 7,25 & \\
\hline R10 & 5,8 & \multirow{3}{*}{5,8} & 6,63 & \multirow{3}{*}{6,67} \\
\hline R11 & 5,8 & & 6,67 & \\
\hline R12 & 5,8 & & 6,71 & \\
\hline
\end{tabular}

A formação de metano, segundo Weiland (2010), ocorre numa faixa de pH entre 6,5 e 8,5 com um intervalo ótimo entre 7,0 e 8,0. Ressalta, ainda, que o processo é severamente inibido se o pH diminui abaixo de 6,0 ou sobe acima de 8,5. O valor do pH aumenta pelo acúmulo de amônia durante a degradação de proteínas, enquanto o acúmulo de ácidos graxos voláteis diminui o valor do pH. Sendo assim, nota-se que a geração de biogás pode não ter alcançado sua potencialidade máxima, devido ao fato de iniciar o processo com um pH ácido. Notou-se, porém, um aumento significativo do pH após os processos de digestão anaeróbia, atingindo valores próximos à neutralidade na saída de todos os Biodigestores estudados.

Em se tratando da produção de biogás, o Biodigestor RE22, como pode ser observado na Figura 5, 
apresentou maior produção de biogás ao longo das primeiras doze horas de experimento. Segundo Liu et al. (2017), tal fato pode ser explicado pela presença do inóculo contido no sistema, que age mais acentuadamente no início do processo de biodigestão. O biogás quantificado neste período alcançou um total de $0,48 \mathrm{dm}^{3}$.

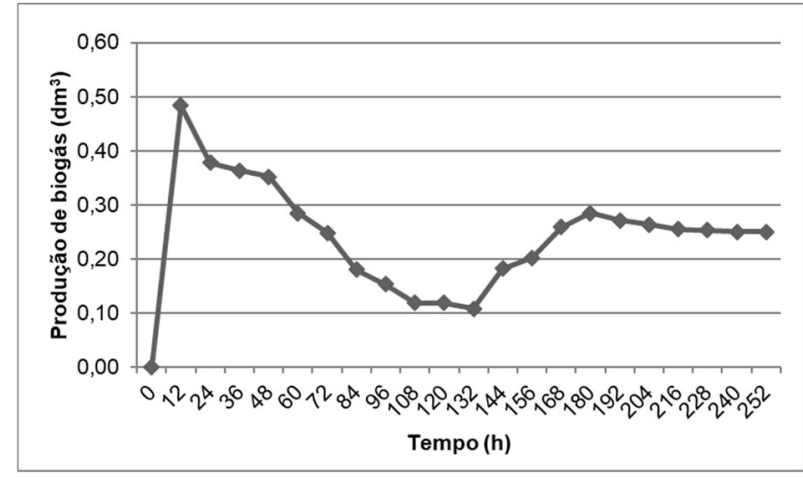

Figura 5: Produção de biogás do Biodigestor RE22.

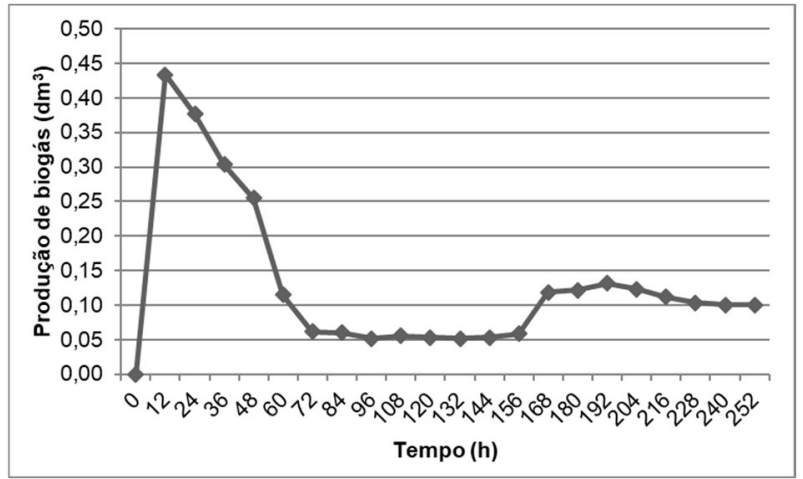

Figura 6: Produção de biogás do Biodigestor R22.

Como pode ser observado na Figura 6, o Biodigestor R22 também obteve maior produção de biogás ao longo das primeiras doze horas de experimento. Quando comparado com o Biodigestor RE22, no entanto, a geração de biogás neste período alcançou um resultado inferior, totalizando $0,43 \mathrm{dm}^{3}$.

O Biodigestor RE35, neste mesmo período, produziu um volume de $1,0 \mathrm{dm}^{3}$ de biogás, obtendo produção superior a todos os sistemas estudados. Este fato pode ser explicado pela composição dos resíduos orgânicos, bem como pela temperatura em que operou (Figura 7).

Assim como nos sistemas anteriores, o Biodigestor R35 obteve pico de produção nas primeiras doze horas de experimento. Neste período alcançou uma produção de $0,72 \mathrm{dm}^{3}$ de biogás (Figura 8). Quando comparado aos Biodigestores RE22 e R22, alcançou maior proximidade à produção alcançada pelo Biodigestor RE35.

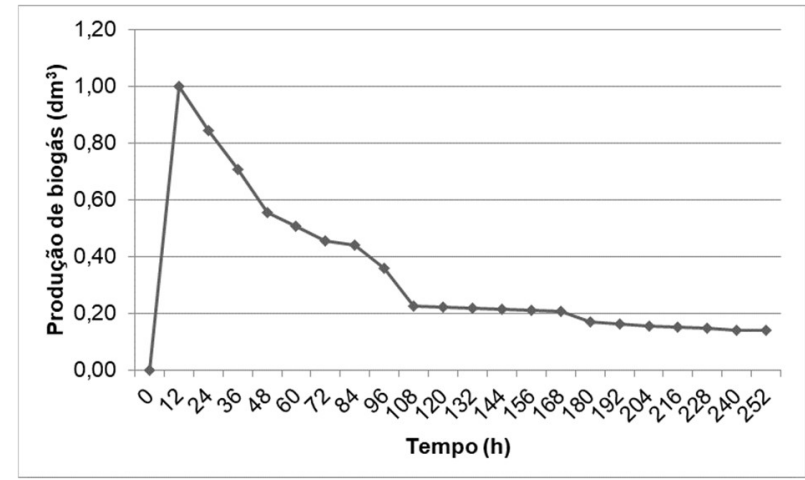

Figura 7: Produção de biogás do Biodigestor RE35.

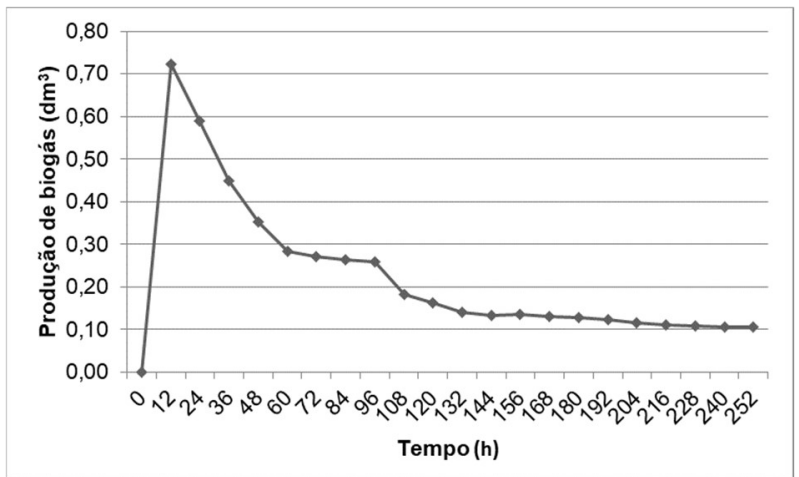

Figura 8: Produção de biogás do Biodigestor R35.

Após o término do experimento adicionou-se um volume de $0,213 \mathrm{dm}^{3}$ a cada Biodigestor, resultando no volume total de biogás produzido, como pode ser observado na Figura 9. Este volume equivale ao reservado para funcionar como headspace. 


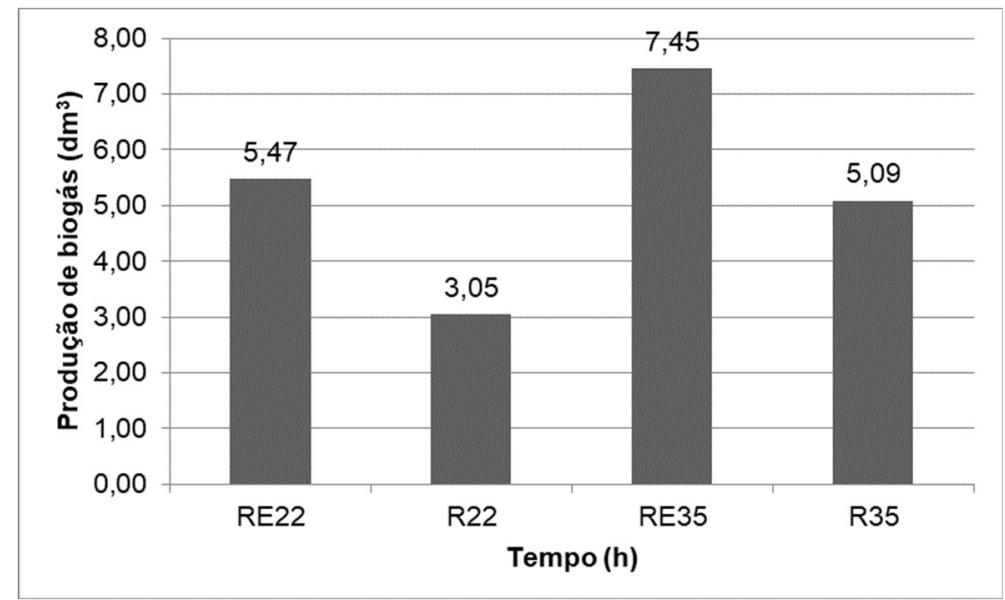

Figura 9: Produção total de biogás.

Como evidenciado na Figura 9, os Biodigestores que continham efluente industrial além dos resíduos alimentares obtiveram melhores resultados, o que indica que não somente a temperatura influencia na produção de biogás, mas a composição do substrato também interfere no resultado final.

Quando comparados entre si, o Biodigestor RE mantido à $35^{\circ} \mathrm{C}$ obteve melhores resultados que o Biodigestor RE mantido à $22^{\circ} \mathrm{C}$, o que indica que quando há um mesmo substrato, a temperatura é fator de grande influência na produção de biogás.

De acordo com Nadaleti et al. (2018), que estudaram as temperaturas mesófilas e termófilas para a produção de biogás através da biodigestão anaeróbia do efluente da parboilização de arroz, utilizando como inóculo o lodo obtido do UASB da indústria, a temperatura de $35^{\circ} \mathrm{C}$ (mesófila) apresentou maior produção de biogás.

Lourenço (2017) avaliou o potencial de produção de biogás via codigestão do efluente da parboilização de arroz com casca de banana à $35^{\circ} \mathrm{C}$, onde obteve-se produção de até $8,49 \mathrm{dm}^{3} \mathrm{em} 168$ horas de experimento em um biodigestor com volume total de $2,15 \mathrm{dm}^{3}$. Neste mesmo período de tempo, o Biodigestor com melhor resultado (RE35) obteve uma produção de aproximadamente $6,17 \mathrm{dm}^{3}$, resultado que pode ser considerado satisfatório visto que o biodigestor do presente estudo possui menos da metade do volume do biodigestor estudado por Lourenço (2017).

Garcia-Peña et al. (2011) avaliaram a viabilidade da produção de metano a partir de resíduos de carne, frutas e vegetais obtidos do mercado central de distribuição de alimentos na Cidade do México

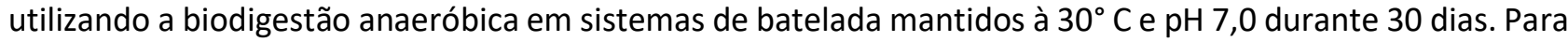
a determinação da remoção da matéria orgânica utilizou-se a análise de Demanda Química de Oxigênio (DQO), onde obteve-se uma remoção de, aproximadamente, 65\%. Nota-se que está remoção foi superior à obtida pelo Biodigestor R22, o qual obteve remoção estimada em 51,61\%. Em contrapartida, os Biodigestores R35, RE22 e RE35 obtiveram remoções superiores, alcançando 68,45, 79,96 e 92,17\%, respectivamente.

Um estudo realizado por Tayyab et al. (2019) avaliou o potencial da codigestão anaeróbica de resíduos alimentares e erva daninha Parthenium em bioreatores de escala laboratorial para produção de biogás à $30 \pm 1^{\circ} \mathrm{C}$. Dentre os parâmetros de desempenho do bioprocesso avaliou-se a DQO, constatando-se uma eficiência na remoção de matéria orgânica de, aproximadamente, 79\% em 60 dias de experimento, 
resultado inferior aos obtidos pelos Biodigestores RE22 e RE35.

Evidenciou-se, portanto, o potencial energético dos diferentes resíduos orgânicos produzidos no município de Pelotas. Estudos futuros, porém, são necessários visando potencializar a produção de biogás, bem como tornar o aproveitamento energético economicamente viável.

\section{CONCLUSÕES}

Os sistemas de codigestão anaeróbia realizados nesse estudo obtiveram resultados positivos em relação à produção de biogás. Quando comparados entre si, constatou-se que os Biodigestores contendo efluente industrial e resíduos alimentares obtiveram uma maior produção total de biogás quando comparados aos Biodigestores contendo apenas resíduos alimentares. Este fato pode ser explicado pela composição variável dos resíduos contidos nos Biodigestores.

A temperatura mostrou-se fator determinante quando comparadas as produções de biogás entre Biodigestores contendo o mesmo substrato, podendo-se concluir que a temperatura de $35^{\circ} \mathrm{C}$ mostrou-se mais favorável para a codigestão anaeróbia.

Em busca de soluções ambientalmente viáveis para estes resíduos, esta pesquisa apresentou um método de aproveitamento de resíduos orgânicos industriais e urbanos. Ressalta-se que a produção de biogás deve ser incentivada, visto que pode proporcionar além das vantagens ambientais, benefícios econômicos.

\section{REFERÊNCIAS}

APHA; AWWA; WEF. American Public Health Association; American Water Works Association; Water Environment Federation. Standard Methods for the Examination of Water and Wastewater. Washington: APHA, 2005.

BALAT, M.; BALAT, H.. Biogás as a renewable energy source: a review. Energy Sources, Part A: Recovery, Utilization and Environmental Effects, v.31, p.1280-1293, 2009. DOI: https://doi.org/10.1080/15567030802089565

BUGGENHOUT, J.; BRIJS, K.; CELUS, I.; DELCOUR, J. A.. The breakage susceptibility of raw and parboiled rice: a review. Journal of Foof Engineeering, v.117, p.304-315, 2013. DOI: https://doi.org/10.1016/i.jfoodeng.2013.03.009

CARNEIRO, D. R. C.. Viabilidade Técnica e Económica de uma Unidade Centralizada de Co-Digestão Anaeróbia de Resíduos Orgânicos. Dissertação (Mestrado de Engenharia do Ambiente) - Universidade do Porto, Porto, 2009.

FAO. Food and Agriculture Organization of the United Nations. FAO statistical yearbook 2014: Latin America and the Caribbean food and agriculture. FAO, 2014.

FAO. Food and Agriculture Organization of the United Nations. Rice market monitor. FAO, 2018.

FARIA, O. L. V.; KOETZ, P. R.; SANTOS, M. S.; NUNES, W. A.. Remoção de fósforo de efluentes da parboilização de arroz por absorção biológica estimulada em reator em batelada sequencial (RBS). Revista Ciência e Tecnologia de Alimentos, Campinas, v.26, n.2, p.309-317, 2006. DOI: http://dx.doi.org/10.1590/S0101-20612006000200013

GARCIA-PEÑAA, E. I.; PARAMESWARAN, P.; KANG, D. W.; CANUL-CHAN, M.; KRAJMALNIK-BROWN, R.. Anaerobic digestion and co-digestion processes of vegetable and fruit residues: Process and microbial ecology. Bioresource Technology, v.102, p.9447-9455, 2011. DOI: https://doi.org/10.1016/j.biortech.2011.07.068

GONZÁLEZ-SÁNCHEZ, M. E.; PÉREZ-FABIELA, S.; WONGVILLARREAL, A.; BELLO-MENDOZA, R.; YAÑEZ-OCAMPOA, G. Residuos agroindustriales con potencial para la producción de metano mediante la digestión anaerobia. Revista Argentina de Microbiología, v.47, p.229-235, 2015. DOI: https://doi.org/10.1016/j.ram.2015.05.003

KIM, M.; AHN, Y.; SPEECE, R.. Comparative process stability and efficiency of anaerobic digestion; mesophilic vs. thermophilic. Water Research, v.36, p.4369-4385, 2002. DOI: https://doi.org/10.1016/S0043-1354(02)00147-1

KOUPAIE, E. H.; LEIVA, M. B.; ESKICIOGLU, C.; DUTIL, C.. Mesophilic batch anaerobic co-digestion of fruit-juice industrial waste and municipal waste sludge: Process and cost-benefit analysis. Bioresource Technology, v.152, p.6673, 2014. DOI:

https://doi.org/10.1016/j.biortech.2013.10.072 
LEITE, V. D.; BARROS, A. J. M.; MENEZES, J. M. C.; SOUSA, J. T.; LOPES, W. S.. Codigestão anaeróbia de resíduos orgânicos. Revista DAE, v.65, n.208, p.35-46, 2017. DOI: https://doi.org/10.4322/dae.2017.004

LIU, T.; SUN, L.; SCÜNURER, B. M. A.. Importance of inoculum source and initial community structure for biogas production from agricultural substrates. Bioresource Technology, v.245, p.768-777, 2017. DOI: https://doi.org/10.1016/j.biortech.2017.08.213

\section{LOURENÇO, V. A.. Produção de biogás via codigestão} anaeróbia de efluente da parboilização do arroz e resíduos sólidos orgânicos. Monografia (Bacharelado em Engenharia Ambiental e Sanitária) - Universidade Federal de Pelotas, Pelotas, 2017.

NADALETI, W. C.; LOURENÇO, V. A.; SCHOELER, G. P.; AFONSO, M.; SANTOS, R. F.; VIEIRA, B. M.; LEANDRO, D.; QUADRO, M. S.. Temperaturas mesófilas e termófilas na produção de biogás através de efluente da parboilização do arroz. Revista Brasileira de Engenharia e Sustentabilidade, v.5, n.1, p.17-21, 2018. DOI: http://dx.doi.org/10.15210/rbes.v5i1.12540

NOTARNICOLA, B.; TASSIELLI, G.; RENZULLI, P. A.; CASTELLANI, V.; SALA, S.. Environmental impacts of food consumption in Europe. Journal of Cleaner Production, v.140, p.753-765, 2017. DOI:

https://doi.org/10.1016/j.jclepro.2016.06.080
SITORUS, B.; SUKANDAR; PANJAITANC, S. D.. Biogas recovery from anaerobic digestion process of mixed fruit and vegetable wastes. Energy Procedia, v.32, p.176-182, 2013. DOI: https://doi.org/10.1016/i.egypro.2013.05.023

SITTIPOD, S.; SHI, Y.. Changes in physicochemical properties of rice starch during steeping in the parboiling process. Journal of Cereal Science, v.69, p.398-405, 2016. DOI: https://doi.org/10.1016/j.jcs.2016.05.010

TAYYAB, A.; AHMAD, Z.; MAHMOOD, T.; KHALID, A.; QADEER, S.; MAHMOOD, S.; ANDLEEB, S.; ANJUM, M.. Anaerobic co-digestion of catering food waste utilizing Parthenium hysterophorus as co-substrate for biogás production. Biomass and Bioenergy, v.124, p.74-82, 2019. DOI: https://doi.org/10.1016/i.biombioe.2019.03.013

TANENTZAP, A. J.; LAMB, A.; WALKER, S.; FARMER, A.. Resolving conflicts between agriculture and the natural environment. PLOS Biology, v.13, p.1-13, 2015. DOI: https://doi.org/10.1371/journal.pbio.1002242

THEMELIS, N. J.; ULLOA, P. A.. Methane generation in landfills. Renewable Energy, v.32, p.1243-1257, 2007. DOI: https://doi.org/10.1016/j.renene.2006.04.020

WEILAND, P.. Biogas production: current state and perspectives. Applied Microbiology and Biotechnology, v.85, p.849-860, 2010. DOI: https://doi.org/10.1007/s00253$\underline{009-2246-7}$

A CBPC - Companhia Brasileira de Produção Científica (CNPJ: 11.221.422/0001-03) detém os direitos materiais desta publicação. Os direitos referem-se à publicação do trabalho em qualquer parte do mundo, incluindo os direitos às renovações, expansões e disseminações da contribuição, bem como outros direitos subsidiários. Todos os trabalhos publicados eletronicamente poderão posteriormente ser publicados em coletâneas impressas sob coordenação da Sustenere Publishing, da Companhia Brasileira de Produção Científica e seus parceiros autorizados. Os (as) autores (as) preservam os direitos autorais, mas não têm permissão para a publicação da contribuição em outro meio, impresso ou digital, em português ou em tradução. 